Original Research

\title{
Does Daily Physical Activity Differ Between Patients with Femoroacetabular Impingement Syndrome and Patients with Hip Dysplasia? A Cross-Sectional Study in 157 Patients and 60 Healthy Volunteers
}

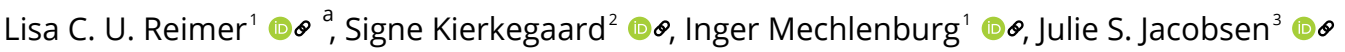 \\ 1 Department of Orthopaedic Surgery, Aarhus University Hospital, Aarhus, Denmark; Department of Clinical Medicine, Aarhus University, Aarhus, \\ Denmark, ${ }^{2}$ Department of Clinical Medicine, Aarhus University, Aarhus, Denmark; H-Hip, Department of Physio and Occupational Therapy and \\ Orthopedic Surgery, Horsens Hospital, Horsens, Denmark, ${ }^{3}$ Research Centre for Health and Welfare Technology, Programme for Rehabilitation \& \\ Department of Physiotherapy, VIA University College, Aarhus, Denmark; Research Unit for General Practice in Aarhus, Aarhus, Denmark \\ Keywords: physical activity, accelerometry, hip dysplasia, femoroacetabular impingement syndrome \\ https://doi.org/10.26603/001c.25523
}

International Journal of Sports Physical Therapy

Vol. 16, Issue 4, 2021

\section{Background}

The clinical presentation of femoroacetabular impingement syndrome (FAIS) and acetabular hip dysplasia (HD) are similar. However, the groups seem to differ regarding physical activity (PA) and sport.

\section{Purpose}

The aim was to compare PA between three groups; patients with FAIS, patients with HD, and healthy volunteers. A secondary purpose was to compare self-reported function in sport and recreation (sport/recreation) between patients with FAIS and HD.

\section{Study Design}

This study is a cross-sectional study on 157 patients with FAIS or HD and 60 healthy controls.

\section{Methods}

PA was measured with accelerometer-based sensors, and sport/recreation was measured with the Copenhagen Hip and Groin Outcome Score (HAGOS). Data on patients with FAIS or HD and healthy volunteers were collected in other studies and merged for comparison in this study.

\section{Results}

Fifty-five patients with FAIS (20 males; mean age 36 years), 97 patients with HD (15 males; mean age 30 years) and 60 healthy volunteers (24 males; mean age 31 years) were included. Compared with patients with HD, patients with FAIS spent more time on very low intensity PA (mean 73 minutes (95\% CI: 45;102)) and less time on low intensity PA per day (mean -21 minutes (95\% CI: -37;-6)). Both groups spent less time on high intensity PA per day compared with healthy volunteers $(\mathrm{p} \leqslant 0.03)$. However, sport/ recreation did not differ between the two groups (FAIS: median 34 points (IQR: 22;50) and HD: median 38 points (IQR: $25 ; 53$ ), $\mathrm{p}=0.16$ ).

\section{Conclusion}

Patients with FAIS appear to be less physical active compared with patients with HD.

\footnotetext{
a Corresponding author:

Lisa C. U. Reimer

Department of Orthopaedic Surgery, Aarhus University Hospital

Palle Juul-Jensens Boulevard 99, 8200 Aarhus, Denmark

E-mail: lisareimer@clin.au.dk

Telephone: +4526474080
} 
However, both groups seem to perform less high intensity PA compared with healthy volunteers. This is interesting, as self-reported function in sport/recreation does not differ between patients with FAIS and HD. Thus, high intensity PA seems to be a key outcome in the management of patients with FAIS and HD.

\section{Level of Evidence}

Level $2 b$

\section{INTRODUCTION}

Femoroacetabular impingement syndrome (FAIS) and acetabular hip dysplasia (HD) are two of the most common hip diseases in young and middle-aged adults ${ }^{1}$ and diagnosed radiographically by acetabular and femoral angles and clinical symptoms of hip pain. ${ }^{2}$ Patients with FAIS either have pincer morphology, which is an over-coverage of the femoral head, ${ }^{3}$ cam morphology, consisting of a bump at the neck-head junction of the proximal femur, ${ }^{4}$ or a combination of the two. HD is typically described as a shallow and steep acetabulum with insufficient coverage of the femoral head. ${ }^{5}$ The literature describes patients with FAIS as athletic males, 6,7 and focus in research has thus been on return to sport. ${ }^{8}$ In contrast, patients with HD are primarily females $^{2}$ and only few studies have investigated their athletic status and return to sport. ${ }^{9}$ Thus, the clinical perception of the two groups seems to differ regarding physical activity (PA) and sport.

According to World Health Organization (WHO), PA includes the following four dimensions: Frequency, Intensity, Time and Type (F.I.T.T.). ${ }^{10}$ To obtain information on these dimensions of PA in daily living, accelerometer-based measurements by small, wearable sensors is considered ideal. ${ }^{11,12}$ Accelerometer-based PA have previously been investigated before and after hip preservation surgery in two cohorts of patient with FAIS or HD. ${ }^{13,14}$ Neither of the two cohorts changed accelerometer-based PA from before to one year after surgery. ${ }^{13,14}$ To the best of the authors' knowledge, no previous studies have compared accelerometer-based PA between patients with FAIS and HD.

The aim of this study was to compare accelerometerbased PA, including the four dimensions of F.I.T.T., between three groups: patients with FAIS, patients with HD, and healthy volunteers. A secondary purpose was, to compare self-reported function in sport and recreation (sport/recreation) between patients with FAIS and HD.

\section{METHODS}

This cross-sectional study combined data from two previously published studies on patients with FAIS (HAFAI cohort study) ${ }^{13}$ and HD, ${ }^{14}$ and healthy volunteers from the ongoing PreserveHip trial. ${ }^{15}$ Data from healthy volunteers from the HAFAI cohort study and the PreserveHip trial were combined. Ethical approval from the Central Denmark Region Committee on Health Research Ethics and the Danish Data Protection Agency was obtained for each study and has been reported in the above mentioned studies. ${ }^{13-15}$

\section{PATIENTS}

Patients with FAIS were included from the Department of Orthopedics at Horsens Hospital. The patients were diagnosed with FAIS according to the Warwick agreement ${ }^{16}$ and scheduled for hip arthroscopy. Further details on inclusion and exclusion criteria have been described previously. ${ }^{17}$

Patients with HD were included from the Department of Orthopedics at Aarhus University Hospital. The patients were diagnosed with HD (Wiberg Center-Edge angle $<25^{\circ}$ and groin pain for at least three months) and scheduled for periacetabular osteotomy. Exclusion criteria have been described elsewhere. ${ }^{18}$

In the HAFAI cohort study and the PreserveHip trial, the healthy volunteers were recruited by advertisements at Horsens Hospital, Aarhus University, Aarhus University Hospital, VIA University College and social media. Healthy volunteers were not considered eligible if they had experienced hip-related pain or problems within the prior year, had a history of previous major surgery on the hip, knee, ankle, back or if they had a neurological or rheumatoid disease affecting their hip function. In addition, healthy volunteers from the PreserveHip trial had a maximum Body Mass Index (BMI) of 25 since patients with a BMI above 25 were not candidates for periacetabular osteotomy. This was not the case for the healthy volunteers from the HAFAI cohort study, where BMI above 25 was not a part of the exclusion criteria.

\section{DATA COLLECTION}

Information on the participants' daily PA was obtained with tri-axial accelerometry. Accelerometers of the model AX3 from Axivity Ltd. (Newcastle, UK) were used for patients with FAIS and healthy volunteers, while accelerometers of the model X16-mini from Gulf Coast Data Concepts (Waveland, MS, USA) were used for patients with HD. The accelerometers measured accelerations in three dimensions at $100 \mathrm{~Hz}$ for the AX3 model and $50 \mathrm{~Hz}$ for the X16-mini model. The accelerometers were worn on the lower extremity not scheduled for surgery and on the right leg for the healthy volunteers. The accelerometers were positioned at the lateral side of the thigh, halfway between the major trochanter and the lateral femoral condyle. Patients with FAIS and healthy volunteers from the HAFAI cohort study wore the accelerometer for five consecutive days. Patients with HD and healthy volunteers from the PreserveHip trial wore the accelerometer for seven consecutive days. All participants were asked to remove the accelerometer when sleeping and during swimming activities. The accelerometer used for the patients with HD was an older version that had to be removed before showering and recharged during nights. The participants were asked to make notes if and for 
how long the accelerometer had been removed during the day. Accelerometers were returned to the hospitals afterwards.

\section{DATA ANALYSIS}

When the accelerometer and the participants' notes were returned, data were downloaded using OMGUI Configuration and Analysis Tool (Version 1.0.0.43, Newcastle, UK). Data were then divided into days using a MatLab (MathWorks, Natick, USA) script developed at Aarhus University Hospital. After separating the datafile into days, data were analyzed using a validated algorithm. ${ }^{19}$ In short, each day was manually calibrated by selecting a period of walking, which enabled the algorithm to precisely identify different types of activities, such as number of steps, cadence of the stepping activity and the time spent walking, based on the average magnitudes of the three acceleration vectors and the gait cycle frequency. ${ }^{19}$ Based on this information, the algorithm also constructed an intensity parameter where each 10-second data window was grouped into one of the following four categories; (i) very low intensity PA e.g. sitting or standing (0-0.05 g), (ii) low intensity PA (0.05-0.1 g) e.g. standing or shuffling, (iii) moderate intensity PA (0.1-0.2 g) e.g. slow or normal walking and (iv) high intensity PA (>0.2 g) e.g. fast walking, running or jumping. ${ }^{19}$ Further details has been described by Lipperts et al. 19

\section{SELF-REPORTED FUNCTION IN SPORT/RECREATION}

Self-reported hip function was obtained from The Copenhagen Hip and Groin Outcome Score (HAGOS). ${ }^{20}$ The subscale sport/recreation was the primary interest of this study, due to the possible difference in athletic status between the two disease groups. The questionnaire consists of five additional subscales: pain, symptoms, physical function in daily living, participation in physical activities and hip- and/or groin-related quality of life. Each subscale is converted into a score from 0 -100, where a score of 100 indicates absence of hip-related problems. The HAGOS has been found to be reliable, valid, and responsive. ${ }^{20,21}$ The Minimal Important Change (MIC) of the subscale sport/ recreation was 11 points in a cohort of Swedish patients with FAIS scheduled for hip arthroscopy. ${ }^{22}$

\section{STATISTICAL CONSIDERATIONS}

Each day was analyzed separately and days containing less than eight hours were excluded. Moreover, since wear time varied between each participant, time spent on each physical activity parameter was normalized to total wear time at the individual level. Before initiating the statistical analyses, all continuous data were assessed for normality using histograms and probability plots. Normally distributed data were presented as means with standard deviations (SD) while non-normally distributed data were presented as medians with interquartile range (IQR), i.e. 25-75th percentile. Categorical data were presented as number of events with percentages of total events. The student t-test and the chisquare test was used to investigate if the groups differed regarding baseline characteristics. Differences between pa- tients with FAIS and patients with HD on the different parameters of F.I.T.T. were investigated using multiple linear regression analyses. These analyses were adjusted for sex for two reasons. Firstly, the proportion of males within the two diseases differs significantly, ${ }^{2}$ and secondly, males were expected to perform more high impact PA than females. The Mann-Whitney U test was used to compare the non-normally distributed HAGOS subscales scores between patients with FAIS and patients with HD. Statistical analyses were performed using STATA 16.1 (StataCorp, College Station, TX, USA). This study was based on participants from other prospective studies. Thus, no sample size calculation was performed as the numbers of participants were fixed when planning this study.

\section{RESULTS}

Sixty patients with FAIS, 100 patients with HD and 66 healthy volunteers were included in this study (Figure 1). Fourteen patients could not be included in the analyses due to missing data. Three days among two patients with FAIS and ten days among eight healthy volunteers were excluded as these days contained less than eight hours of data. None of the patients with HD had worn the accelerometer for less than eight hours. Characteristics of participants revealed that there were fewer males among the patients with HD compared with patients with FAIS. In addition, patients with FAIS were older and had higher BMI compared with patients with HD (Table 1). Accelerometer-based PA for the three groups, described by the dimensions of F.I.T.T. is presented in Table 2.

\section{DIFFERENCES IN ACCELEROMETER-BASED PA BETWEEN PATIENTS WITH FAIS, HD AND HEALTHY VOLUNTEERS}

Compared with patients with HD, patients with FAIS spent more time on very low intensity PA and less time on low intensity PA (Table 3). However, patients with FAIS had worn the accelerometer for more time than patients with HD. Compared with healthy volunteers, patients with FAIS and HD spent less time on high intensity PA, running and cycling, and were more sedentary. However, patients with FAIS spent more time on very low intensity PA compared with healthy volunteers. Adjusting for sex did not change any of the results considerably. Noteworthy, two patients (one with FAIS and one with HD) had a considerably different PA level. Therefore, data from these patients were considered outliers. Accordingly, a sensitivity analyses were done without data on these patients, showing no changes of the results.

\section{DIFFERENCES IN SELF-REPORTED SPORT/RECREATION BETWEEN PATIENTS WITH FAIS AND HD}

Self-reported sport/recreation did not differ between patients with FAIS and patients with HD, and there were no differences in the other subscales of HAGOS between patients with FAIS and HD. Compared to the healthy volunteers, the patients reported about half the score of the healthy volunteers or lower, indicating that the patients are severely impaired by their hip disease. 
Table 1. Characteristics of patients and healthy volunteers with accelerometer-based data.

\begin{tabular}{|c|c|c|c|c|}
\hline & $\begin{array}{l}\text { FAIS } \\
(n=55)\end{array}$ & $\begin{array}{c}\mathrm{HD} \\
(\mathrm{n}=97)\end{array}$ & $\begin{array}{c}p \text {-value } \\
\text { (FAIS vs. HD) }\end{array}$ & $\begin{array}{l}\text { Healthy volunteers } \\
\qquad(n=60)\end{array}$ \\
\hline \multicolumn{5}{|l|}{ Characteristics } \\
\hline Sex, no. males (\%) & $20(36)$ & $15(15)^{a}$ & 0.003 & $24(40)$ \\
\hline Mean age, years (SD) & $36(9)^{a}$ & $30(9)$ & $<0.001$ & $31(9)$ \\
\hline Mean weight, kg (SD) & $76.5(15.3)^{a}$ & $67.8(11.1)$ & $<0.001$ & $66.9(9.6)$ \\
\hline Mean height, m (SD) & $1.73(0.1)$ & $1.71(0.1)$ & 0.06 & $1.73(0.1)$ \\
\hline Mean BMI, kg/m² (SD) & $31(5)^{a}$ & $23(3)^{a}$ & $<0.001$ & $27(2)$ \\
\hline \multicolumn{5}{|l|}{ HAGOS, median (IQR) } \\
\hline Pain & $53(40-68)^{a}$ & $53(38-65)^{a}$ & 0.74 & $100(100-100)$ \\
\hline Symptoms & $46(32-61)^{a}$ & $50(36-61)^{a}$ & 0.38 & $100(96-100)$ \\
\hline Physical function in daily living & $50(35-70)^{a}$ & $55(40-75)^{a}$ & 0.54 & $100(100-100)$ \\
\hline Physical function in sport/recreation & $34(22-50)^{a}$ & $38(25-53)^{a}$ & 0.16 & $100(100-100)$ \\
\hline Participation in physical activities & $13(0-38)^{a}$ & $13(0-38)^{a}$ & 0.67 & $100(100-100)$ \\
\hline Quality of life & $30(25-40)^{a}$ & $30(20-35)^{a}$ & 0.40 & $100(110-100)$ \\
\hline
\end{tabular}

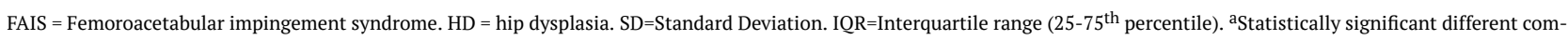
pared with healthy volunteers.

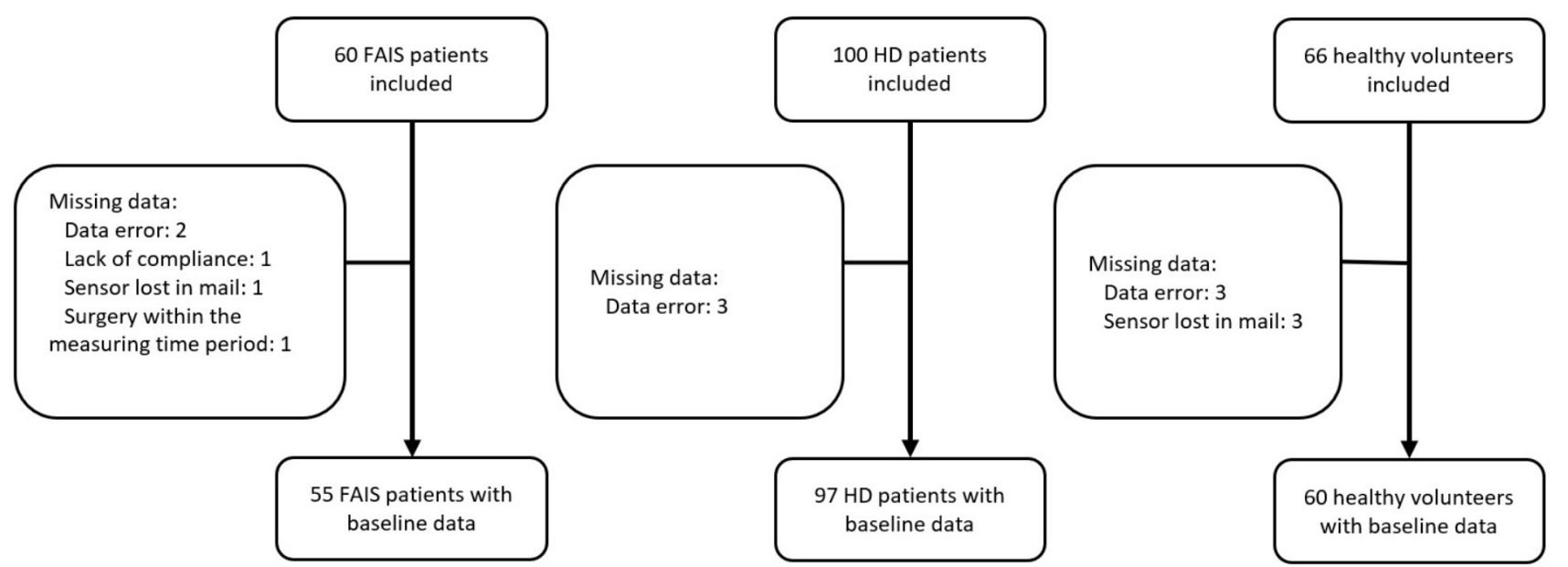

Figure 1. Flow chart of patients and healthy volunteers.

\section{DISCUSSION}

Accelerometer-based PA, described by the four dimensions of F.I.T.T. differed between patients with FAIS and HD regarding time spent on very low and low intensity PA. Compared with patients with HD, patients with FAIS spent 73 minutes more time per day on very low intensity PA and 21 minutes less time per day on low intensity PA. The difference in accelerometer wear time between the two groups may explain the difference in time spent on very low intensity PA. Patients with FAIS wore the accelerometer for an average of 47 minutes longer per day compared with patients with HD. Since both groups were instructed to wear the accelerometer during all waking hours, late evening wear time could be characterized by sedentary PA, possibly explaining the difference in time spent on very low intensity PA. This is further supported by the findings of no dif- ferences in number of steps, cadence, time on high intensity PA, number of sit to stand transfers and time spent on walking, standing and cycling between patients with FAIS and HD. In addition, there were no differences between the two groups in any of the HAGOS subscales.

Compared with the healthy volunteers, patients with FAIS spent less time on low and high intensity PA. In contrast to the results of this study, Kierkegaard et al. did not find a difference in time spent on different intensity PA's between patients with FAIS and healthy volunteers. ${ }^{13}$ This indicates that the difference found in this study could be related to the sampling of healthy volunteers collected in the PreserveHip trial ${ }^{15}$ or that the bigger sample improves chances of finding a statistically significant difference. Patients with HD differed from the healthy volunteers on time spent on high intensity PA, with a 14 minutes difference per day. Compared with the healthy volunteers, patients with 
Table 2. Physical activity per day in patients with FAIS, patients with HD and healthy volunteers described by the dimensions of F.I.T.T.

\begin{tabular}{|llccc|}
\hline & & & & Healthy volunteers \\
& & FAIS & HD & (n=60) \\
Dimension & & $(\mathrm{n}=55)$ & $(\mathrm{n}=97)$ & Mean (SD) \\
Frequency & Parameter & Mean (SD) & Mean (SD) & $7904(2534)$ \\
Intensity & Steps total, no. & $8038(3348)$ & $7696(2849)$ & $98.9(7.0)$ \\
& Cadence, steps/min & $97.3(7.3)$ & $98.3(6.7)$ & $622(118)$ \\
& Very low intensity PA, min & $713(82)$ & $639(85)$ & $116(43)$ \\
& Low intensity PA, min & $100(43)$ & $121(47)$ & $60(22)$ \\
Time & Moderate intensity PA, min & $52(24)$ & $57(25)$ & $50(22)$ \\
& High intensity PA, min & $40(25)$ & $38(18)$ & $847(103)$ \\
& Wear time, min & $904(91)$ & $855(69)$ & $97(29)$ \\
& Walking, min & $101(39)$ & $99(37)$ & $246(74)$ \\
& Standing, min & $254(83)$ & $220(84)$ & $485(95)$ \\
& Sedentary, min & $541(107)$ & $529(104)$ & $4(7)$ \\
& Running, min & $1(2)$ & $1(3)$ & $15(12)$ \\
& Cycling, min & $7(12)$ & $55(21)$ & $55(13)$ \\
\hline
\end{tabular}

Results are presented as mean with standard deviations (SD). Abbreviations: FAIS=Femoroacetabular impingement syndrome; HD=hip dysplasia; F.I.T.T.=frequency, intensity, time and type; no.=number, min=minutes; $\mathrm{PA}=$ physical activity.

FAIS and HD spent more time per day being sedentary, revealing a more inactive lifestyle, possibly a consequence of the hip disease or sequelae related to the hip disease. In addition, patients also differed form healthy volunteers regarding time spent on high intensity PA (e.g. fast walking, running or jumping, etc.), indicating that the longstanding hip disease or sequelae related to the hip disease possibly prevented the patients from performing these activities. Therefore, high intensity PA seems to be a key outcome when managing patients with FAIS and HD.

Health professionals are advised to highlight the benefits of meeting PA recommendations (i.e. 150 minutes of moderate intensity aerobic PA or 75 minutes of high intensity aerobic PA per week). In this study, patients with FAIS performed 52 minutes of moderate intensity PA per day and 40 minutes of high intensity PA per day. Patients with HD performed 57 minutes of moderate intensity PA per day and 38 minutes of high intensity PA per day. The healthy volunteers performed 60 minutes of moderate intensity PA per day and 50 minutes of high intensity PA per day. Hence, the two patient groups and the healthy volunteers met the weekly recommendations regarding daily PA. Patients as well as the healthy volunteers had a mean of daily steps close to 8000 , with a cadence close to 100 . This is in accordance with the minimum recommendations for physical activity reported by Tudor-Locke et al., who estimated the minimum amount of daily steps to be $7000-8000$ for healthy adults, with a cadence on 100 steps per minute. ${ }^{23}$

Harris-Hayes et al. investigated the number of strides per day in 74 patients with FAIS and 24 patients with HD, using a step watch. ${ }^{24}$ They found that patients with FAIS had an average of 5095 daily strides (corresponding to 10,190 steps per day), while patients with HD had an average of 4627 daily strides (corresponding to 9254 steps per day). ${ }^{24}$
Accordingly, the number of daily steps found by HarrisHayes et al. is higher than the average number of daily steps found in the current study, suggesting that the patients in our study could be more impaired by their underlying hip disease or had a lower daily PA level. In addition, Harris-Hayes et al. found that the number of daily strides for patients with FAIS and HD were similar to the number of daily strides for a group of 20 asymptomatic controls. ${ }^{24}$ The asymptomatic controls had an average of 5192 daily strides (corresponding to 10,384 steps per day), which was also considerably higher compared with the healthy volunteers in the current study. ${ }^{24}$ This indicates that the differences could be due to the two different methods used to measure steps and strides.

The current study has several strengths. Firstly, the usage of a validated algorithm, which ensures the validity of the estimates. ${ }^{19}$ Secondly, the accelerometer wear time covered both weekends and weekdays for at least eight hours a day. Thirdly, the adjustment of analyses, based on the assumption that sex could be a confounder for the association between hip problems and PA. However, the adjusted analysis revealed that sex was not a confounder for the association between hip disease and PA. The study, however, also has some limitations. Firstly, the usage of two different accelerometer-based sensors could negatively have impacted on the wear time of the sensor used by the patients, since the sensor worn by patients with HD had to be removed before showering as well as recharged during the night. In addition, the older sensor was sampling at a lower frequency than the newer model. The different sensors could have explained some of the difference regarding wear time between the two patient groups. However, wear time was not different between patients with HD and healthy volunteers, although PA of the volunteers was measured with 
Table 3. Mean differences in physical activity per day between patients with FAIS and HD described by the dimensions of F.I.T.T.

\begin{tabular}{|c|c|c|c|c|c|}
\hline \multirow[b]{2}{*}{ Dimension } & \multirow[b]{2}{*}{ Parameter } & \multicolumn{4}{|c|}{ Mean differences between FAIS and HDa } \\
\hline & & $\begin{array}{l}\text { Unadjusted mean (95\% } \\
\qquad \mathrm{Cl})\end{array}$ & $\begin{array}{c}\mathrm{p}- \\
\text { value }\end{array}$ & $\begin{array}{l}\text { Adjusted }^{\mathrm{C}} \text { mean }(95 \% \\
\text { Cl) }\end{array}$ & $\begin{array}{c}\mathrm{p}- \\
\text { value }\end{array}$ \\
\hline Frequency & Steps total, no. & $342(-671 ; 1355)$ & 0.51 & $445(-600 ; 1489)$ & 0.40 \\
\hline \multirow[t]{5}{*}{ Intensity } & Cadence, steps/min & $-1.0(-3.3 ; 1.3)$ & 0.40 & $-0.5(-2.9 ; 1.9)$ & 0.67 \\
\hline & Very low intensity PA, min & $74(46 ; 102)$ & $<0.001$ & $73(45 ; 102)$ & $<0.001$ \\
\hline & Low intensity PA, min & $-21(-36 ;-6)$ & 0.01 & $-21(-37 ;-6)$ & 0.01 \\
\hline & $\begin{array}{l}\text { Moderate intensity PA, } \\
\text { min }\end{array}$ & $-5(-14 ; 3)$ & 0.19 & $-7(-15 ; 2)$ & 0.12 \\
\hline & High intensity PA, min & $2(-5 ; 9)$ & 0.51 & $2(-5 ; 9)$ & 0.65 \\
\hline \multirow[t]{6}{*}{ Time } & Wear time, min & $50(24 ; 76)$ & $<0.001$ & $47(20 ; 74)$ & 0.001 \\
\hline & Walking, min & $2(-11 ; 14)$ & 0.76 & $2(-11 ; 15)$ & 0.71 \\
\hline & Standing, min & $34(6 ; 62)$ & 0.02 & $36(8 ; 65)$ & 0.01 \\
\hline & Sedentary, min & $12(-23 ; 47)$ & 0.49 & $7(-29 ; 43)$ & 0.71 \\
\hline & Running, min & $0.06(-0.87 ; 0.98)$ & 0.90 & $-0.02(-0.98 ; 0.93)$ & 0.96 \\
\hline & Cycling, min & $2(-2 ; 5)$ & 0.39 & $1(-2 ; 5)$ & 0.46 \\
\hline \multirow[t]{2}{*}{ Type } & Sit to stand transfers, no. & $0.1(-6.5 ; 6.7)$ & 0.98 & $1.2(-5.6 ; 8.0)$ & 0.72 \\
\hline & & \multicolumn{4}{|c|}{ Mean differences between FAIS and healthy volunteers ${ }^{b}$} \\
\hline Dimension & Parameter & $\begin{array}{l}\text { Unadjusted mean (95\% } \\
\text { Cl) }\end{array}$ & $\begin{array}{c}\mathrm{p}- \\
\text { value }\end{array}$ & $\begin{array}{l}\text { Adjusted }{ }^{\mathrm{C}} \text { mean }(95 \% \\
\mathrm{Cl})\end{array}$ & $\begin{array}{c}\mathrm{p}- \\
\text { value }\end{array}$ \\
\hline Frequency & Steps total, no. & $134(-957 ; 1225)$ & 0.81 & $79(-983 ; 1141)$ & 0.88 \\
\hline \multirow[t]{5}{*}{ Intensity } & Cadence, steps/min & $-1.6(-4.3 ; 1.0)$ & 0.22 & $-1.7(-4.3 ; 1.0)$ & 0.22 \\
\hline & Very low intensity PA, min & $91(53 ; 128)$ & $<0.001$ & $92(55 ; 129)$ & $<0.001$ \\
\hline & Low intensity PA, min & $-16(-32 ; 0.03)$ & 0.05 & $-16(-32 ;-0.4)$ & 0.05 \\
\hline & $\begin{array}{l}\text { Moderate intensity PA, } \\
\text { min }\end{array}$ & $-8(-16 ; 0.6)$ & 0.07 & $-8(-17 ; 0.4)$ & 0.06 \\
\hline & High intensity PA, min & $-9(-18 ;-1)$ & 0.03 & $-10(-18 ;-1)$ & 0.02 \\
\hline \multirow[t]{6}{*}{ Time } & Wear time, min & $57(21 ; 93)$ & 0.002 & $58(22 ; 94)$ & 0.002 \\
\hline & Walking, min & $4(-9 ; 17)$ & 0.54 & $4(-9 ; 16)$ & 0.59 \\
\hline & Standing, min & $8(-21 ; 38)$ & 0.57 & $9(-20 ; 38)$ & 0.54 \\
\hline & Sedentary, min & $56(18 ; 93)$ & 0.004 & $56(19 ; 94)$ & 0.003 \\
\hline & Running, min & $-3(-5 ;-1)$ & 0.003 & $-3(-5 ;-1)$ & 0.003 \\
\hline & Cycling, min & $-8(-12 ;-3)$ & 0.001 & $-8(-12 ;-3)$ & 0.001 \\
\hline \multirow[t]{2}{*}{ Type } & Sit to stand transfers, no. & $-0.1(-5.8 ; 5.6)$ & 0.98 & $0.01(-5.7 ; 5.7)$ & 1.00 \\
\hline & & \multicolumn{4}{|c|}{ Mean differences between HD and healthy volunteers ${ }^{b}$} \\
\hline Dimension & Parameter & $\begin{array}{l}\text { Unadjusted mean (95\% } \\
\qquad \mathrm{Cl})\end{array}$ & $\begin{array}{c}\mathrm{p}- \\
\text { value }\end{array}$ & $\begin{array}{l}\text { Adjusted }^{\mathrm{C}} \text { mean }(95 \% \\
\mathrm{Cl})\end{array}$ & $\begin{array}{c}\mathrm{p}- \\
\text { value }\end{array}$ \\
\hline Frequency & Steps total, no. & $-208(-1095 ; 679)$ & 0.64 & $-558(-1461 ; 346)$ & 0.23 \\
\hline \multirow[t]{5}{*}{ Intensity } & Cadence, steps/min & $-0.7(-2.9 ; 1.6)$ & 0.56 & $-1.2(-3.5 ; 1.1)$ & 0.29 \\
\hline & Very low intensity PA, min & $17(-15 ; 49)$ & 0.30 & $26(-6 ; 59)$ & 0.11 \\
\hline & Low intensity PA, min & $5(-10 ; 20)$ & 0.51 & $2(-13 ; 17)$ & 0.78 \\
\hline & $\begin{array}{l}\text { Moderate intensity PA, } \\
\text { min }\end{array}$ & $-3(-10 ; 5)$ & 0.53 & $-4(-13 ; 4)$ & 0.28 \\
\hline & High intensity PA, min & $-12(-18 ;-5)$ & $<0.001$ & $-14(-21 ;-8)$ & $<0.001$ \\
\hline \multirow[t]{5}{*}{ Time } & Wear time, min & $7(-20 ; 35)$ & 0.59 & $10(-18 ; 38)$ & 0.49 \\
\hline & Walking, min & $2(-9 ; 13)$ & 0.73 & $-2(-13 ; 10)$ & 0.78 \\
\hline & Standing, min & $-26(-52 ; 0.3)$ & 0.05 & $-21(-48 ; 6)$ & 0.13 \\
\hline & Sedentary, min & $44(11 ; 76)$ & 0.01 & $45(11 ; 79)$ & 0.01 \\
\hline & Running, min & $-3(-5 ;-1)$ & $<0.001$ & $-3(-4 ;-1)$ & 0.002 \\
\hline
\end{tabular}




\begin{tabular}{|llcccc|} 
& Cycling, in & $-9(-13 ;-6)$ & $<0.001$ & $-10(-13 ;-6)$ & $<0.001$ \\
Type & Sit to stand transfers, no. & $-0.1(-6.0 ; 5.7)$ & 0.96 & $-0.05(-6.2 ; 6.1)$ & 0.99 \\
\hline
\end{tabular}

Results are presented as mean with $95 \%$ confidence interval (95\% CI). ${ }^{\text {a }}$ Reference group is patients with HD. ${ }^{b}$ Reference group is healthy volunteers. ${ }^{\mathrm{c} A d j u s t e d}$ for sex. Abbreviations: FAIS=Femoroacetabular impingement syndrome; $\mathrm{HD}=$ hip dysplasia; F.I.T.T.=frequency, intensity, time and type; $\mathrm{PA}=$ physical activity.

the newer accelerometer. In addition, time spent on different activities was normalized to total wear time at the individual level. Therefore, the usage of two different accelerometer models does not seem to have influenced our results. Secondly, the daily PA level of the healthy volunteers may be overestimated due to some degree of volunteer bias as participation is probably associated with health consciousness and an active lifestyle. In addition, the healthy volunteers had to meet the predefined inclusion criteria which may have resulted in being healthier and more active than the average Danish citizen. However, a great effort was done to minimize healthy volunteer bias by including volunteers from many different institutions as well as the patient's own network. Thirdly, several comparisons were made which by chance will increase the chance of finding a false significant result. However, all comparisons were formulated prior to the statistical analyses. Therefore, multiple comparison bias is not considered problematic in this study.

\section{CONCLUSION}

Patients with FAIS appear to be less physically active compared with patients with HD. However, both groups seem to perform less high intensity PA compared with healthy volunteers. This is interesting, as self-reported function in sport/recreation does not differ between patients with FAIS and HD. Thus, high intensity PA seems to be a key outcome in the management of patients with FAIS and HD.

\section{CONFLICT OF INTEREST}

None.

\section{ACKNOWLEDGEMENTS}

The authors would like to thank Louise Mortensen for helping with the data collection, Bernd Grimm and Matthijs Lipperts for developing the MatLab algorithm and Peter Bo Jørgensen for developing the MatLab script used for analysis. The authors would also like to thank Marianne Tjur and Erhard Næss-Schmidt for thorough introduction to the analysis method.

\section{FUNDING}

This work was supported by Aase og Ejnar Danielsen Fond, Augustinus Fonden, Direktør Jacob Madsen og Hustru Olga Madsens Fond, Familien Hede Nielsens Fond, Familien Kjaersgaard Sunds Fond, Fonden til Lægevidenskabens Fremme, Gurli og Hans Engell Friis Foundation, Horsens Regional Hospital, the Association of Danish Physiotherapists, the Danish Foundation of Physically Disabled Persons, the Danish Rheumatism Association and the Health Research Fund for the Central Denmark Region. The foundations only delivered financial support and had no role in planning or performing the study.

Submitted: February 22, 2021 CDT, Accepted: May 03, 2021

CDT 


\section{REFERENCES}

1. Reiman MP, Agricola R, Kemp JL, et al. Consensus recommendations on the classification, definition and diagnostic criteria of hip-related pain in young and middle-aged active adults from the International Hiprelated Pain Research Network, Zurich 2018. Br J Sports Med. 2020;54:631-641. doi:10.1136/bjsports-20 19-101453

2. Belzile EL, Beaule PE, Ryu J-J, et al. Outcomes of joint preservation surgery: comparison of patients with developmental dysplasia of the hip and femoroacetabular impingement. J Hip Preserv Surg. 2016;3(4):270-277. doi:10.1093/jhps/hnw033

3. Ganz R, Parvizi J, Beck M, Leunig M, Nötzli H, Siebenrock KA. Femoroacetabular impingement: a cause for osteoarthritis of the hip. Clin Orthop Relat Res. 2003;(417):112-120. doi:10.1097/01.blo.0000096 $\underline{804.78689 . c 2}$

4. Ito K, Leunig M, Werlen S. Femoroacetabular impingement and the cam-effect. A MRI-based quantitative anatomical study of the femoral headneck offset. J Bone Jt Surg. 2001;83(2):171-176. doi:1 $\underline{0.1302 / 0301-620 x .83 b 2.11092}$

5. Mechlenburg I, Nyengaard JR, Rømer L, Søballe K. Changes in load-bearing area after Ganz periacetabular osteotomy evaluated by multislice CT scanning and stereology. Acta Orthop Scand. 2004;75(2):147-153. doi:10.1080/00016470412331294 $\underline{395}$

6. Agricola R, Bessems JHJM, Ginai AZ, et al. The development of cam-type deformity in adolescent and young male soccer players. Am J Sports Med. 2012;40(5):1099-1106. doi:10.1177/036354651243838 1

7. Byrd JWT, Jones KS. Arthroscopic management of femoroacetabular impingement in athletes. Am J Sports Med. 2011;39(Supplement 1):7S-13S. doi:10.11 77/0363546511404144

8. Ishøi L, Thorborg K, Kraemer O, et al. Return to sport and performance after hip arthroscopy for femoroacetabular impingement in 18- to 30-year-old athletes: a cross-sectional cohort study of 189 athletes. Am J Sports Med. 2018;46(11):2578-2587. do i:10.1177/0363546518789070

9. Heyworth BE, Novais EN, Murray K, et al. Return to play after periacetabular osteotomy for treatment of acetabular dysplasia in adolescent and young adult athletes. Am J Sports Med. 2016;44(6):1573-1581. do i: $10.1177 / 0363546516632743$
10. Cavill N, Kahlmeier S, Racioppi F. Physical Activity and Health in Europe: Evidence for Action. WHO Library Cataloguing in Publication Data; 2006.

11. Verlaan L, Bolink SAA, Van Laarhoven S, et al. Accelerometer-based physical activity monitoring in patients with knee osteoarthritis: objective and ambulatory assessment of actual physical activity during daily life circumstances. Open Biomed Eng J. 2015;9(1):157-163. doi:10.2174/187412070150901015 7

12. Sliepen M, Lipperts M, Tjur M, Mechlenburg I. Use of accelerometer-based activity monitoring in orthopaedics: benefits, impact and practical considerations. EFORT Open Rev. 2019;4(December):678-685. doi:10.1302/2058-524 $\underline{1.4 .180041}$

13. Kierkegaard S, Dalgas U, Lund B, Lipperts M, Søballe K, Mechlenburg I. Despite patient-reported outcomes improve, patients with femoroacetabular impingement syndrome do not increase their objectively measured sport and physical activity level 1 year after hip arthroscopic surgery. Results from the HAFAI cohort. Knee Surgery, Sport Traumatol Arthrosc. 2019. doi:10.1007/s00167-019-05503-5

14. Jacobsen JS, Thorborg K, Holmich P, et al. Does the physical activity profile change in patients with hip dysplasia from before to 1 year after periacetabular osteotomy? Acta Orthop. 2018;89(6):622-627. doi:10.1080/17453674.2018.1531 $\underline{492}$

15. Reimer LCU, Jakobsen SS, Mortensen L, et al. Efficacy of periacetabular osteotomy followed by progressive resistance training compared to progressive resistance training as non-surgical treatment in patients with hip dysplasia (PreserveHip) - a protocol for a randomised controlled trial. BMJ Open. 2019;9:e032782. doi:10.11 36/bmjopen-2019-032782

16. Griffin DR, Dickenson EJ, O’Donnell J, et al. The Warwick Agreement on femoroacetabular impingement syndrome (FAI syndrome): an international consensus statement. Br J Sports Med. 2016;50(19):1169-1176. doi:10.1136/bjsports-2016-09 $\underline{6743}$

17. Kierkegaard S, Lund B, Dalgas U, Sørensen H, Søballe K, Mechlenburg I. The Horsens-Aarhus Femoro Acetabular Impingement (HAFAI) cohort: outcome of arthroscopic treatment for femoroacetabular impingement. Protocol for a prospective cohort study. BMJ Open. 2015;5(9):1-8. do i:10.1136/bmjopen-2015-008952 
18. Jacobsen JS, Holmich P, Thorborg K, et al. Muscletendon-related pain in 100 patients with hip dysplasia: prevalence and associations with selfreported hip disability and muscle strength. J Hip Preserv Surg. 2018;5(1):39-46. doi:10.1093/jhps/hnx04 1

19. Lipperts M, van Laarhoven S, Senden R, Heyligers I, Grimm B. Clinical validation of a body-fixed 3D accelerometer and algorithm for activity monitoring in orthopaedic patients. J Orthop Transl. 2017;11:19-29. doi:10.1016/i.jot.2017.02.003

20. Thorborg K, Holmich P, Christensen R, et al. The Copenhagen Hip and Groin Outcome Score (HAGOS): development and validation according to the COSMIN checklist. Br J Sports Med. 2011;45(6):478-491. doi:1 $\underline{0.1136 / \text { bjsm.2010.080937 }}$

21. Kemp JL, Collins NJ, Roos EM, Crossley KM. Psychometric properties of patient-reported outcome measures for hip arthroscopic surgery. Am J Sports Med. 2013;41(9):2065-2073. doi:10.1177/0363546513 494173
22. Thomeé R, Jónasson $\mathrm{P}$, Thorborg $\mathrm{K}$, et al. Crosscultural adaptation to Swedish and validation of the Copenhagen Hip and Groin Outcome Score (HAGOS) for pain, symptoms and physical function in patients with hip and groin disability due to femoroacetabular impingement. Knee Surgery, Sport Traumatol Arthrosc. 2014;22(4):835-842. doi:10.1007/ s00167-013-2721-7

23. Tudor-Locke C, Craig CL, Brown WI, et al. How many steps/day are enough? For adults. Int J Behav Nutr Phys Act. 2011;8(79). doi:10.1186/1479-5868-8-7 $\underline{9}$

24. Harris-Hayes M, Steger-May K, Pashos G, Clohisy JC, Prather H. Stride activity level in young and middle-aged adults with hip disorders. Physiother Theory Pract. 2012;28(5):333-343. doi:10.3109/095939 $\underline{85.2011 .639852}$ 